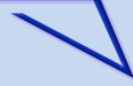

Archive for

Organic Chemistry
Arkivoc 2018, part iv, 76-93

\title{
Overview of enterolactone biological properties and total synthesis
}

\author{
Quinlyn T. Waulters, Waidath Bio-Sawe, Russell Hofmann, and Mukund P. Sibi* \\ Department of Chemistry and Biochemistry, North Dakota State University, NDSU Dept. 2735, \\ P.O. Box 6050 Fargo, ND 58108, United States \\ Email: mukund.sibi@ndsu.edu
}

Dedicated to Prof. Gordon Gribble on the occasion of his retirement and for his outstanding contributions to science and mentoring of students.

Received 12-23-2017

Accepted 02-17-2018

Published on line 03-04-2018

\section{Abstract}

Lignans are a class of compounds found in plants, especially fiber-rich foods such as flax seeds, whole grains, berries and vegetables. A diet rich in lignans is believed to be protective against cancer, inflammation, viral infection, stroke, and cardiovascular diseases. Enterolactone, a mammalian lignan, has been investigated extensively due to its potential therapeutic properties. A variety of approaches to synthesize enterolactone have been reported. This account summarizes some of the biological studies and reported syntheses of enterolactone found in literature.

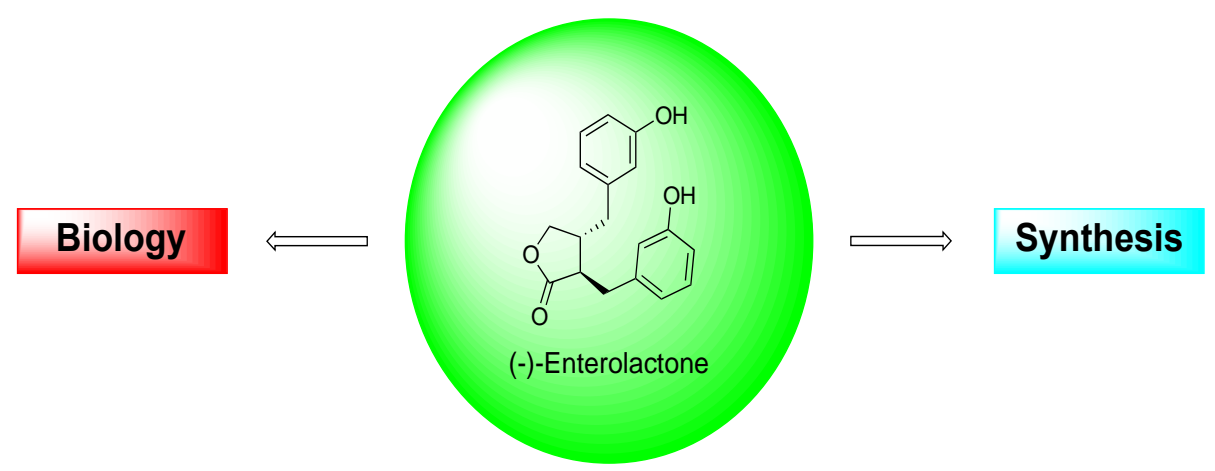

Keywords: Lignan, enterolactone, estrogen, enantioselective synthesis. 


\section{Table of Contents}

1. Introduction

2. Biology Overview of Enterolactone

2.1. Conversion of lignan to enterolactone

2.2. Enterolactone interactions and therapeutic potential

2.3. Biosynthesis of enterolactone

3. Total Synthesis of Enterolactone

3.1. Racemic synthesis of enterolactone

3.2. Enantioselective synthesis of enterolactone

3.2.1. Use of chiral auxiliary

3.2.2. Use of transition metal and organocatalysts

3.2.3. Desymmetrization using enzymes

3.2.4. One pot synthesis of enterolactone

4. Conclusions

5. Acknowledgements

6. References

\section{Introduction}

Lignans, a term coined by R. D. Haworth in 1936, are known to be present in a vast variety of plant families. ${ }^{1,2}$ They are present in the roots, leaves, seeds, bark, and fruit of plants. Some examples of plants containing lignans are flax seed, sunflower seed, wheat, curly kale, garlic, French beans, apricots and more. ${ }^{3-11}$ The backbone of the lignan structure is two phenylpropane units, $C_{6}-C_{3}$, which are produced by plants through oxidative dimerization of two phenylpropanoid units. ${ }^{10,12}$ Enterolactone, the first lignan found present in the mammalian gut, has a chemical structure similar to estrogen. Because of this similarity, enterolactone acts like estrogen and is able to bind to its receptors. Although there are discrepancies in the literature, enterolactone is believed to possess some therapeutic benefits such as antitumor, anti-inflammatory, immunosuppressant, anti-oxidant, antiviral, antimicrobial, and anticancer properties. ${ }^{10,12}$ When lignans are consumed, they travel through the colon, where they are converted into enterolignans-enterolactone and enterodiol-with the help of the intestinal flora. ${ }^{13,14}$ Due to its potential therapeutic properties, the synthesis of enterolactone and its derivatives have attracted much attention. Many reviews have been written on enterolactone, however, the majority of these focused on the properties of enterolactone with few on its synthesis. Here, we outline both the medicinal properties of enterolactone and the various ways in which it has been synthesized.

\section{Biology Overview}

\subsection{Conversion of lignans into enterolactone}

Early on, it was thought that enterolactone was produced only in female ovaries. This was because enterolactone levels vary in females during their menstrual cycle. However, later studies showed that enterolactone arises from the breakdown of plant lignans from fruits, grains, seeds, and vegetables by the gut microbiome, which is present in both males and females. ${ }^{15,16}$ Lignan-rich food ingested is converted into 
enterolactone, which enters the bloodstream through the intestines and is later expelled from the body through urine and fecal matter. ${ }^{17,18}$ Much evidence has been put forward to demonstrate the involvement of bacteria in producing enterolactone. Alexon et al. reported that in a bacteria free environment, there was no secretion of enterolactone in the urine or bile of animals, demonstrating that bacteria in the gut flora are necessary for the breakdown of lignan. ${ }^{19}$

The amount of enterolactone present in the body was highlighted in 1981 by Adlercreutz et al., who demonstrated a positive correlation between lignan intake and the amount of enterolactone present in urine. The study was conducted on four groups of women: young vegetarians, young omnivores (24-27 years old), old vegetarians and old omnivores ( $\geq 50$ years old). The younger omnivore participants had similar fiber intake to that of the older omnivores, while the younger vegetarians had comparable fiber intake to that of the older vegetarian participants. It was found that younger vegetarians secreted more enterolactone in their urine, while younger omnivores have the lowest enterolactone secretion $(5.0 \mathrm{mg} / 24 \mathrm{~h}$ vs $0.57 \mathrm{mg} / 24 \mathrm{~h}$ for young vegetarians and young omnivores, respectively, and $0.64 \mathrm{mg} / 24 \mathrm{~h}$ vs $0.88 \mathrm{mg} / 24 \mathrm{~h}$ for older vegetarians and omnivores, respectively). ${ }^{20}$ Interestingly, this also reveals that the older omnivores had more enterolactone excretion compared to that of the older vegetarians. ${ }^{20} \mathrm{Also}$, the amount of enterolactone present in urine decreases with age in females regardless of fiber intake. Furthermore, Wallström et al. found a positive correlation between age and the levels of enterolactone in Swedish men. ${ }^{21}$ Overall, these findings point out that the levels of enterolactone are dependent not only on the fiber intake but also on the age, sex, and possibly the geographical location of the participants. More studies need to be conducted to confirm these observations and find possible reasons behind these differences.

\subsection{Enterolactone interactions and therapeutic potential}

As previously mentioned, the similarity of enterolactone to estrogen allows it to bind weakly to estrogen receptors and induce estrogenic activities. ${ }^{22}$ Due to these interactions, many studies have been conducted to determine the effects of enterolactone on humans and rats. It was found that high levels of enterolactone correlate to reduced cancer risks, anti-inflammatory properties, and anti-atherosclerosis properties. Studies also revealed that enterolactone can be used as a precautionary measure to prevent stroke, neurodegenerative diseases, and cardiovascular diseases and to relieve menopausal symptoms. ${ }^{22,23}$

Aromatase, an enzyme that converts androgen into estrogen, has been a drug target for breast cancer. ${ }^{24}$ Wang et al. reported that flavonoids, lignans, enterolactone, and enterodiols inhibit aromatase, thereby reducing the risk of breast cancer in postmenopausal women. ${ }^{25}$ This is because estrogen stimulates normal cell growth and the growth of hormone receptor positive cancer cells. Moreover, in their study, Wang et al. showed that enterolactone decreased aromatase activity compared to aminoglutethimide, a first-generation aromatase inhibitor, with $K_{i}$ values of $14.4 \mu \mathrm{M}$ and $0.5 \mu \mathrm{M}$, respectively. However, they estimate that the effect of these lignans alone in vivo may not be sufficient to treat cancer, but a long term supplementation of lignans may promote a reduced risk of cancer. ${ }^{16,25}$

While some studies suggest a negative correlation between cancer and fiber intake, other studies show no correlation. ${ }^{21}$ A study conducted by Keinan-Boker et al. with 15,555 Dutch women diagnosed with breast cancer demonstrated that there is no correlation between the amount of lignan intake and the risk of developing breast cancer. ${ }^{16}$ Although Wallström et al. made the same observations, their study suggested that high lignan intake could be associated with a reduction of symptomatic or high-risk prostate cancer in Swedish men who smoked or had abdominal obesity. ${ }^{13}$ The lack of correlation could be explained by the amount of lignan intake in both populations being too low to obtain any meaningful results. ${ }^{16,21}$ 
Other studies reported beneficial features of enterolactone in the prevention of cardiovascular diseases. It was found that middle-aged Finnish men with high serum levels of enterolactone ( $\geq 23.9 \mathrm{nmol} / \mathrm{L}) \mathrm{had} 45 \%$ and $56 \%$ reduced risks of mortality due to cardiovascular disease and coronary heart disease, respectively. ${ }^{26}$ In addition, for every $10 \mathrm{nmol} / \mathrm{L}$ of enterolactone, the percent reductions in coronary heart disease and cardiovascular disease were $17 \%$ and $13 \%$, respectively. ${ }^{26}$ Overall, the results suggest that when middle-aged Finnish men were injected with high serum levels of enterolactone, a reduced risk of premature death due to cardiovascular and coronary heart disease was observed. ${ }^{26}$

While enterolactone is able to downregulate the formation of estrogen, thus possibly preventing breast cancer in women, men may see other side effects due to an increase in enterolactone. Estrogen is known to play a role in the process of spermatogenesis, and studies have shown that uncontrolled exposure to external estrogen or estrogen-like substances could have a negative impact on male fertility. ${ }^{27-29} \mathrm{~A}$ correlation has been reported between high levels of phytoestrogen and a reduced sperm count. A study conducted by Chavarro et al. at the Massachusetts General Hospital Fertility Center revealed that men who consume a diet rich in phytoestrogen, especially soy foods, have 35 million less sperm $/ \mathrm{mL}$ compared to men who had little phytoestrogen in their diet. ${ }^{28}$ Xia et al. conducted a study which suggested that Chinese men, typically on a high phytoestrogen diet, have a median sperm count of 48.9 million lower than those with a lower phytoestrogen intake. ${ }^{29}$ In light of these studies, it can be concluded that the quantity of lignan consumed can negatively affect male fertility.

In summary, despite the extensive amount of research performed on enterolactone and lignans, it is still unclear whether they are beneficial, harmful, or have no effect on the human body. These conflicting results could be due to variations in individuals' physiology. Levels of enterolactone are dependent on a variety of factors such as an individual's microbiome, medications, genetics, and frequency of elimination. Furthermore, most of these studies lack a systematic way of determining the amount of lignan consumed by the participants. Even though studies do not agree on the properties of enterolactone, researchers seem to agree unanimously that high levels of enterolactone contribute to an overall healthy lifestyle.

\subsection{Biosynthesis of enterolactone}

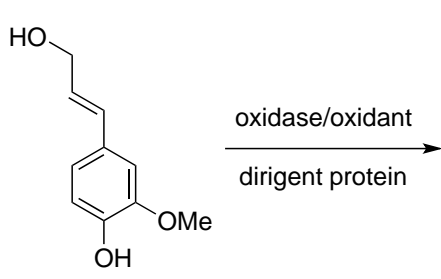

coniferyl alcohol

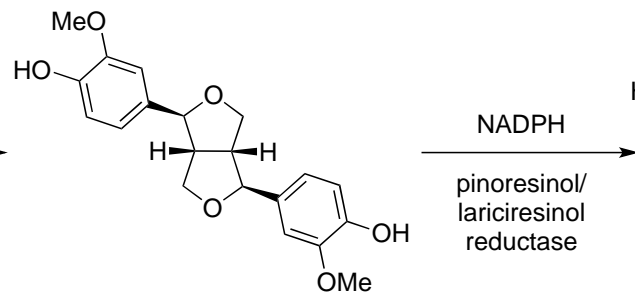

(+)-pinoresinol

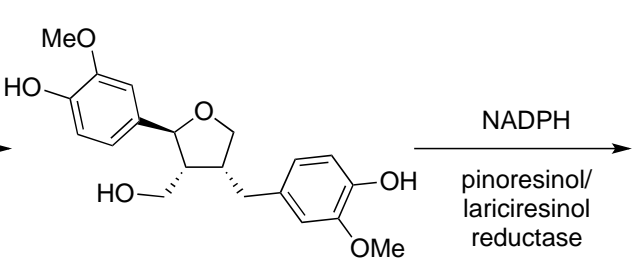

(+)-lariciresinol

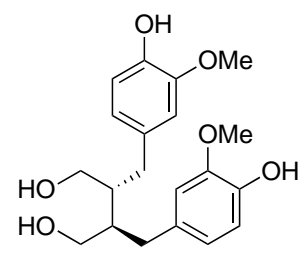

(-)-secoisolariciresinol

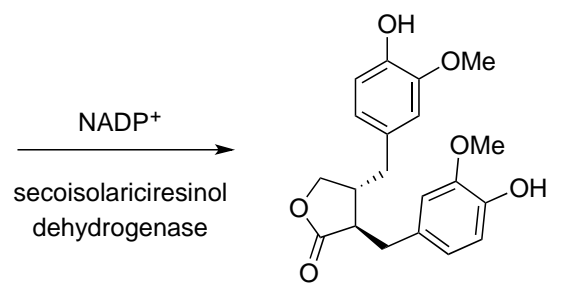

(-)-matairesinol

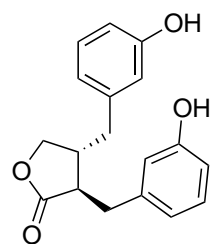

(-)-enterolactone

Scheme 1. Biosynthesis of enterolactone. ${ }^{32}$ 
Lignans are found in the heartwood of plants, and are believed to protect plants from fungi and insects. ${ }^{30,31}$ It has been suggested that lignan biosynthesis starts with the dimerization of coniferyl alcohol through radical coupling mediated by a dimeric dirigent protein. Dirigent proteins, macromolecules that determine the stereochemistry of lignans, bind and position two molecules of coniferyl alcohol to form (+)-pinoresinol, stereoselectively. ${ }^{31}(+)$-Pinoresinol is then converted into (+)-lariciresinol by pinoresinol/lariciresinol reductase; $(+)$-lariciresinol is in turn converted into (-)-secoisolariciresinol. ${ }^{30,31} \mathrm{~A}$ chemoselective oxidation affords (-)matairesinol which, when consumed, is converted into enterolactone via the bacteria present in the gut (Scheme 1)..$^{32,33}$

\section{Total Synthesis of Enterolactone}

\subsection{Racemic syntheses of enterolactone}

The first racemic total synthesis of $\left( \pm\right.$ )-enterolactone was published in 1980 by Groen and Leemhuis. ${ }^{34}$ This racemic synthesis employed the preparation of a $\beta$-substituted $\gamma$-butyrolactone followed by an alkylation to install the $\alpha$-substituent from the less hindered face to establish the required anti stereochemistry (Scheme 2). Cooley and colleagues were able to confirm the structure of enterolactone by utilizing a Stobbe condensation to construct the core framework. ${ }^{35}$ Mahalanabis et al. presented a short synthesis of enterolactone from substituted succinamides in $32 \%$ overall yield. ${ }^{36}$ Another early total synthesis of enterolactone was reported by Asaoka et al., ${ }^{37}$ which utilized a Baeyer-Villiger rearrangement and ring opening in order to provide a racemic mixture or an enantioenriched product depending on the chirality of the starting material. An alternative methodology that allowed access to both enantiomers of enterolactone was reported by Ghosh. ${ }^{38}$ Early in this synthesis a 1:1 mixture of diastereomers obtained from alkylation of a chiral ester enolate was separated by column chromatography and each diastereomer used individually to produce enantiopure (+) or (-)enterolactone. Other syntheses that have been developed employed radical reactions, ${ }^{39,40}$ transition metal catalysts, ${ }^{41,42}$ and conjugate addition ${ }^{43}$ to afford both enterolactone enantiomers. This work paved the way for the enantioselective syntheses of enterolactone, which are discussed below.

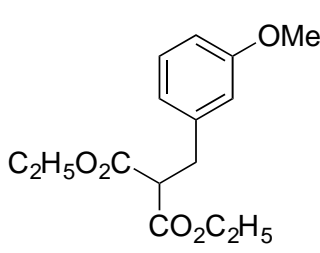

1

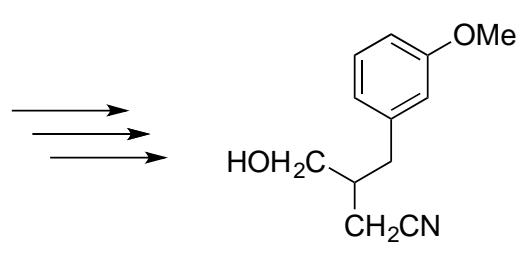

2
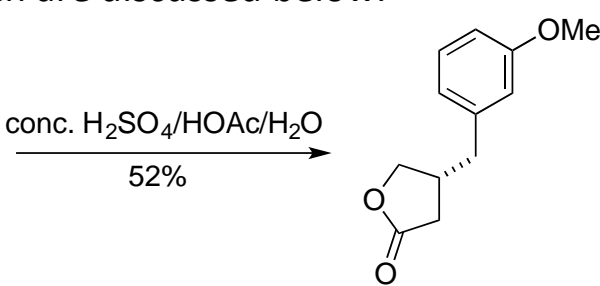

3

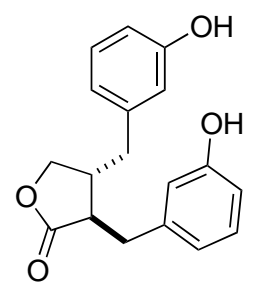

4

$64 \%$

Scheme 2. The first synthesis of enterolactone by Groen et al. ${ }^{34}$ 


\subsection{Enantioselective syntheses of enterolactone}

Several methods can be utilized to obtain the two chiral centers present on the lactone ring selectively in a step wise manner. Some of the strategies used toward this goal include the use of auxiliary groups, metal catalysts, and enzymes in conjunction with reactions such as conjugate addition, radical pathways, carbene chemistry, and cross-metathesis.

\subsubsection{Use of chiral auxiliary}

Over the years, a variety of chiral auxiliaries have been developed to allow the selective formation of carboncarbon bonds. Evans' oxazolidinone based chiral auxiliaries are commonly used for the synthesis of target molecules. ${ }^{44}$ Sibi and co-workers have developed other oxazolidinone- and pyrazolidinone-based auxiliary groups. $^{45}$

In particular, the chiral oxazolidinone 5 was used by Sibi and co-workers to develop an enantiopure synthesis of enterolactone (Scheme 3). ${ }^{46}$ The amide present in the auxiliary group was acylated with monosuccinyl chloride ethyl ester, and the product was then treated with NaHMDS and 3-methoxybenzyl iodide to form the alkylated product 7 in $60 \%$ yield. The directing group on the chiral auxiliary aided in the diastereoselective generation of 7 . The auxiliary group was then cleaved by a chemoselective hydrolysis with the use of lithium hydroxide and hydrogen peroxide to afford an $80 \%$ yield of $\mathbf{8}$, which was then reduced and cyclized to form the lactone 9 in 75\% yield. The lactone 9 was alkylated diastereoselectively a second time, using NaHMDS and 3methoxybenzyl iodide to generate 10 in $69 \%$ yield. ${ }^{34}$ Demethylation of the ethers using boron tribromide furnished (-)-enterolactone 11 in an overall yield of 19\% over seven steps. Using a similar strategy but generating 12 as an intermediate, the synthesis of (+)-enterolactone, 13 , was accomplished in $27 \%$ overall yield over seven steps (Scheme 4). The advantage of this method over other reported syntheses is the ability to access either enantiomer of enterolactone by using a single chiral auxiliary. The chiral auxiliary was recovered in $85 \%$ yield in the cleavage step (Step 3).

Instead of using an ionic pathway as described in Schemes 3 and 4, Sibi and co-workers developed a method where a radical intermediate is generated. Highly reactive radical species have been known to present a challenge for selective reactions, however high selectivities can be achieved when a chiral auxiliary group is incorporated into the substrate. The directing group present on the chiral auxiliary group blocks one face of the substrate, allowing the radical alkylation to occur selectively. This newly formed bond will direct the subsequent chiral center formation, leading to the formation of product diastereoselectively. Furthermore, the radical alkylation pathway could offer an advantage over the reported ionic methods, since benzyl copper or Grignard reagent can be challenging to synthesize (see Scheme 7) whereas this method uses a readily available benzylic halide for alkylation to generate enterolactone. ${ }^{47}$

Sibi and co-workers developed a stepwise synthesis of (-)-enterolactone from a readily available fumarate using radical chemistry (Scheme 5). ${ }^{47}$ (-)-Enterolactone was synthesized through the regio- and diastereoselective addition of two benzylic groups with an initial radical-mediated conjugate addition. The regioand diastereoselectivity of the conjugate radical addition was controlled by chelation of the Lewis acid to the acyl oxazolidinone, which locked the substrate in an s-cis conformation. Moreover, the coordination of the Lewis acid to the acyl imide allowed conjugate addition to take place on the beta carbon, resulting in a regioselective product. A single diastereomer, 15, was obtained in 71\% yield through the radical addition of 3-methoxybenzyl bromide to fumarate 14 using $\mathrm{Sm}(\mathrm{OTf})_{3}$ as the Lewis acid. The second benzylic group was installed in a syn fashion by generation of an enolate with NaHMDS followed by addition of 3-methoxybenzyl iodide to give the dialkylated product 16 with excellent diastereoselectivity and 44\% yield. The conversion of 16 to 11 was completed as in Scheme 3, affording the product in $21 \%$ overall yield over six steps. 
<smiles>O=C1NC(C(c2ccccc2)c2ccccc2)CO1</smiles>

5<smiles>CCOC(=O)CCC(=O)Cl</smiles>

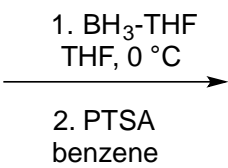

8

$80 \%$<smiles>O=C1OC[C@H](Cc2cccc(O)c2)[C@@H]1Cc1cccc(O)c1</smiles><smiles>CCOC(=O)C[C@@H](Cc1cccc(OC)c1)C(=O)O</smiles>$$
80 \%
$$

$88 \%$<smiles>CCOC(=O)CCC(=O)N1C(=O)OCC1C(c1ccccc1)c1ccccc1</smiles>

6
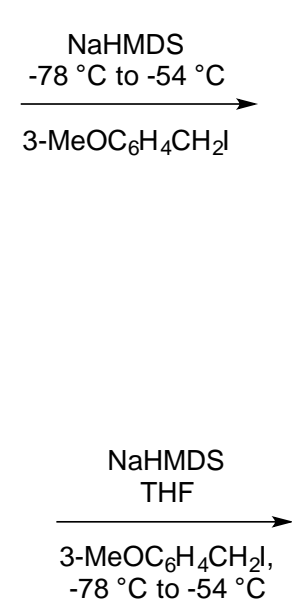<smiles>CCOC(=O)CC(Cc1cccc(OC)c1)C(=O)N1C(=O)OCC1C(c1ccccc1)c1ccccc1</smiles>

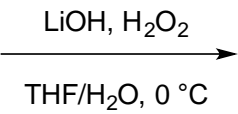

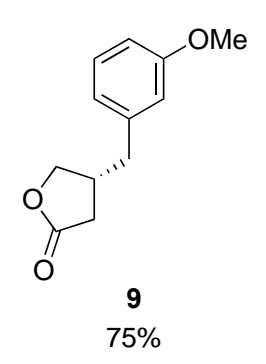

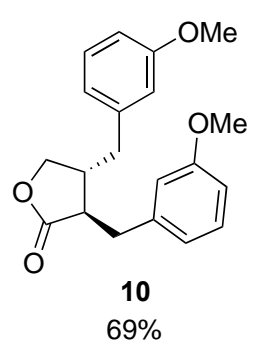

Scheme 3. Synthesis of (-)-enterolactone by Sibi et al. ${ }^{46}$

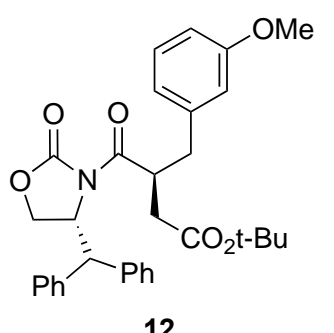

$79 \%$

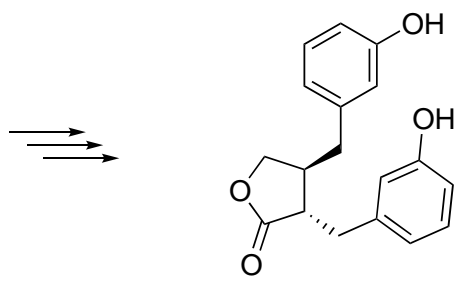

13 $34 \%$

Scheme 4. Synthesis of (+)-enterolactone by Sibi et al. ${ }^{46}$

A chiral oxazolidinone derived from phenylalaninol was employed by Allais et al. to diastereoselectively generate (-)-enterolactone (Scheme 6$).{ }^{2}$ The commercially available starting material, 17 , was first coupled to the chiral oxazolidinone with the use of Evans' procedure, providing 18. ${ }^{48}$ The enantiopure product underwent diastereoselective allylation resulting in 19. Alcohol $\mathbf{2 0}$ was generated by cleaving the chiral auxiliary group. The core lactone ring was then produced in two steps: oxidative cleavage with osmium tetroxide followed by oxidation with Fetizon's reagent to form the lactone 9. Once the lactone ring was formed, the remaining steps were completed in a manner similar to that described in Scheme 3, resulting in a $21 \%$ overall yield over seven steps. 
<smiles>CCOC(=O)/C=C/C(=O)N1C(=O)OCC1C(c1ccccc1)c1ccccc1</smiles>

14<smiles>O=C1OC[C@H](Cc2cccc(O)c2)C1Cc1cccc(O)c1</smiles>

11
$\mathrm{Sm}(\mathrm{OTf})_{3}(1.0 \mathrm{eq})$, $\stackrel{\mathrm{BrCH}_{2} \mathrm{C}_{6} \mathrm{H}_{4}-3-\mathrm{OMe}}{\longrightarrow}$ DCM/THF (4:1) $\mathrm{Bu}_{3} \mathrm{SnH}, \mathrm{Et}_{3} \mathrm{~B} / \mathrm{O}_{2}$, $-78^{\circ} \mathrm{C}$<smiles>CCOC(Cc1cccc(OC)c1)C(COC)CC(=O)N1C(=O)OCC1C(c1ccccc1)c1ccccc1</smiles>

15

$71 \%$
1. NaHMDS, THF, $3-\mathrm{MeOC}_{6} \mathrm{H}_{4} \mathrm{CH}_{2} \mathrm{I}$

$-78^{\circ} \mathrm{C}$ to $-54^{\circ} \mathrm{C}$ 2. $\mathrm{LiOH} / \mathrm{H}_{2} \mathrm{O}_{2}$<smiles>CCOC(=O)C(Cc1cccc(OC)c1)C(Cc1ccccc1)C(=O)O</smiles>

16 $44 \%$

Scheme 5. Formation of a radical intermediate resulting in (-)-enterolactone by Sibi et al. ${ }^{47}$

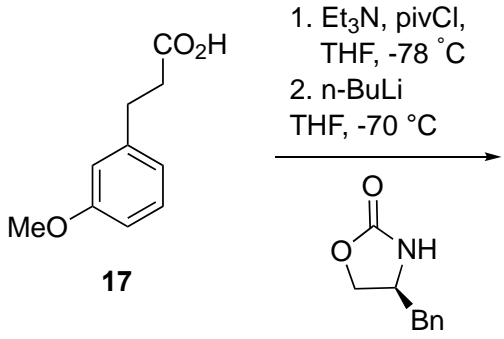

$\overbrace{\text { OMe }}$

20

$71 \%$
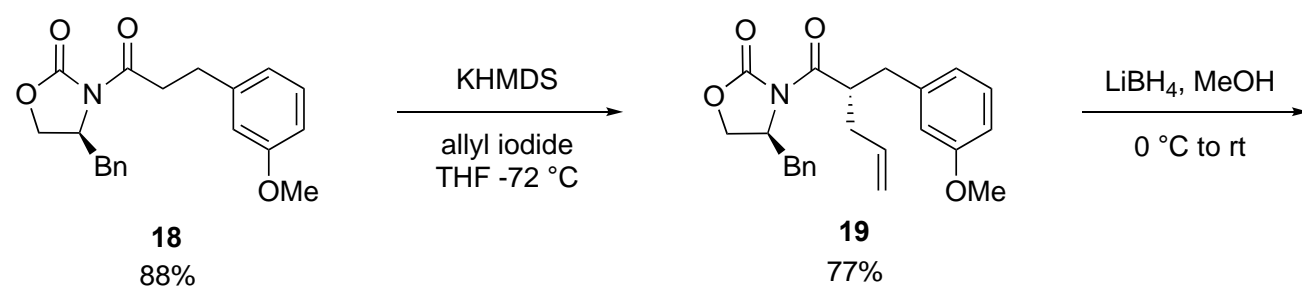

2,6-lutidine

$\underset{\text { 2. } \mathrm{Ag}_{2} \mathrm{CO}_{3} / \text { Celite }}{\stackrel{\text { 1,4-dioxane- } \mathrm{H}_{2} \mathrm{O}}{\longrightarrow}}$

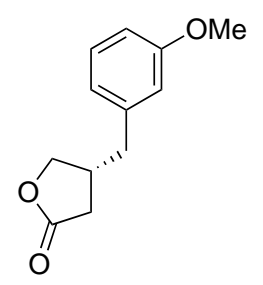

9

$73 \%$

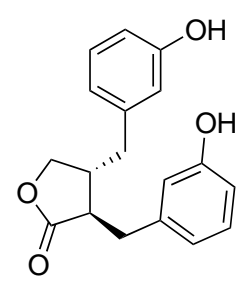

11

$59 \%$

Scheme 6. Synthesis of (-)-enterolactone using Evans' chiral oxazolidinone by Allais et al. ${ }^{2}$

Besides using chiral auxiliaries, the enantioselective synthesis of enterolactone has been accomplished by starting with a optically active compound. Yoda and colleagues started their synthesis with the readily available L-malic acid, 21 (Scheme 7). ${ }^{49}$ They employed conjugate addition, which allowed them to diastereoselectively generate the (-)-enterolactone product. The diacid $\mathbf{2 1}$ was treated sequentially with acetyl chloride, benzylamine and then acetyl chloride to generate the corresponding cyclic imide, 22. Regio- and stereoselective reduction using sodium borohydride provided hemiaminals, which were protected with TBDMSCI to give a mixture of silyl ether intermediates. Epimerization, which plausibly occurs at the reduction step, gave isomers $\mathbf{2 3}$ and $\mathbf{2 4}$ in a ratio of 78:22. Fortunately, the two isomers could be separated, and the major diastereomer, 23, 
was then converted into the corresponding unsaturated lactam, 25. The lactam was subsequently treated with a copper reagent prepared from copper(I) iodide and $m$-methoxybenzylmagnesium chloride in THF to form the conjugate addition adduct, 26, as a single diastereomer. The adduct was converted into a lactone via the removal of the silyl group followed by ring opening of the lactam with sodium borohydride to form hydroxyamide and finally ring closure with $p$-toluenesulfonic acid to form the $(R)$ - $\gamma$-butyrolactone 9 . The second aryl group was installed diastereoselectively by enolate generation with LDA followed by alkylation, and the final (-)-enterolactone, 11, was formed through demethylation to give an overall yield of $5.5 \%$.

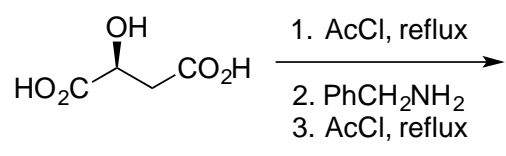

21

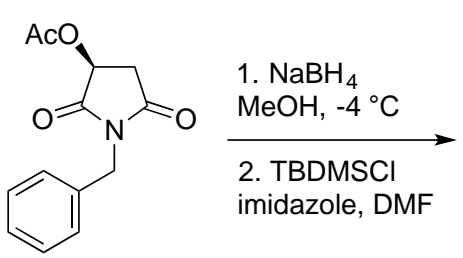

22

$100 \%$

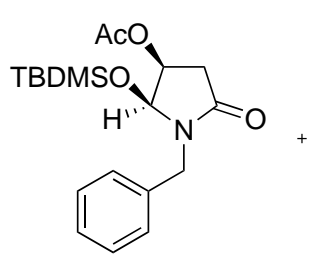

23

$60 \%$

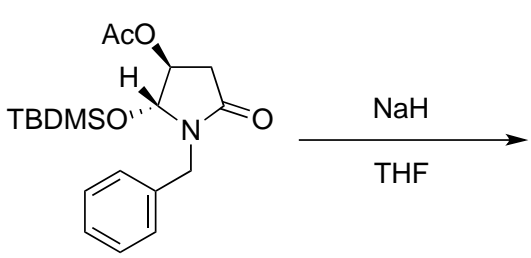

24

$17 \%$

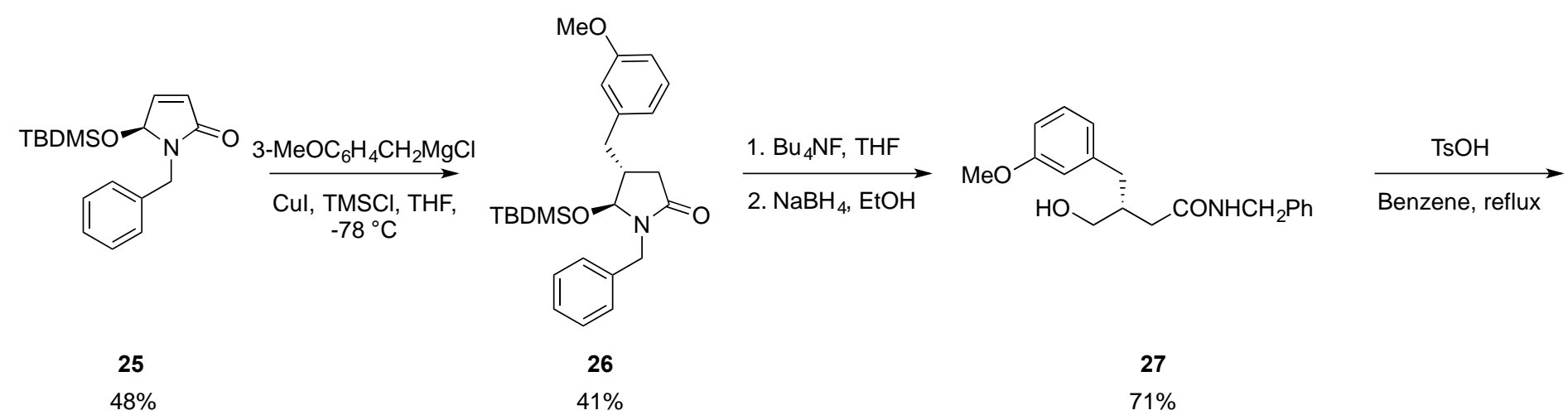

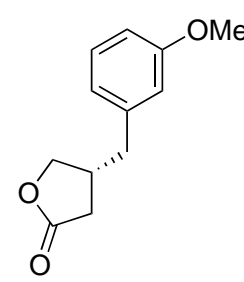

9

$89 \%$<smiles>O=C1OC[C@H](Cc2cccc(O)c2)[C@H]1Cc1cccc(O)c1</smiles>

11

$73 \%$

Scheme 7. Synthesis of (-)-enterolactone from L-malic acid by Yoda et al. ${ }^{49}$

\subsubsection{Use of transition metal catalysts and organocatalysts}

The implementation of homogeneous organometallic catalysts in enterolactone synthesis has led to the showcase of procedures which provide exceptionally enantioenriched products. ${ }^{45,50,51}$ This section will also discuss an organocatalytic approach to the synthesis of enterolactone.

The work of Doyle et al. provided an enantioselective route to butyrolactones via dirhodium(II) catalyzed C$\mathrm{H}$ insertion of carbenes (Scheme 8). ${ }^{50}$ Commercially available $m$-methoxycinnamic acid, 28, was reduced to afford 29. A $\beta$-ketoester was then formed by the reaction of the alcohol and diketene. Using methylsulfonyl 
azide and basic conditions, the $\beta$-ketoester underwent Regitz-like diazo transfer and deacylation to provide the diazoacetate 30, which generated a carbenoid upon refluxing with $\mathrm{Rh}_{2}(4(R)-\mathrm{MPPIM})_{4}$ to give the regioisomer $(R)-\gamma$-butyrolactone 9 exclusively in $63 \%$ yield and $93 \%$ ee. The synthesis of (-)-enterolactone, 11, was completed by the method previously mentioned in a $26 \%$ overall yield (Scheme 3). ${ }^{46,50}$ Changing the catalyst to $\mathrm{Rh}_{2}(4(S)$ $\mathrm{MPPIM})_{4}$ provided the $(S)$ - $\gamma$-butyrolactone enantiomer of 9 , with an overall yield of $27 \%$ and $91 \%$ ee for the total synthesis of $(+)$-enterolactone, $13 .{ }^{50,52}$ Although this method provides moderate yield and good selectivity for enterolactone, it is limited by the difficulty of working with methanesulfonyl azide.
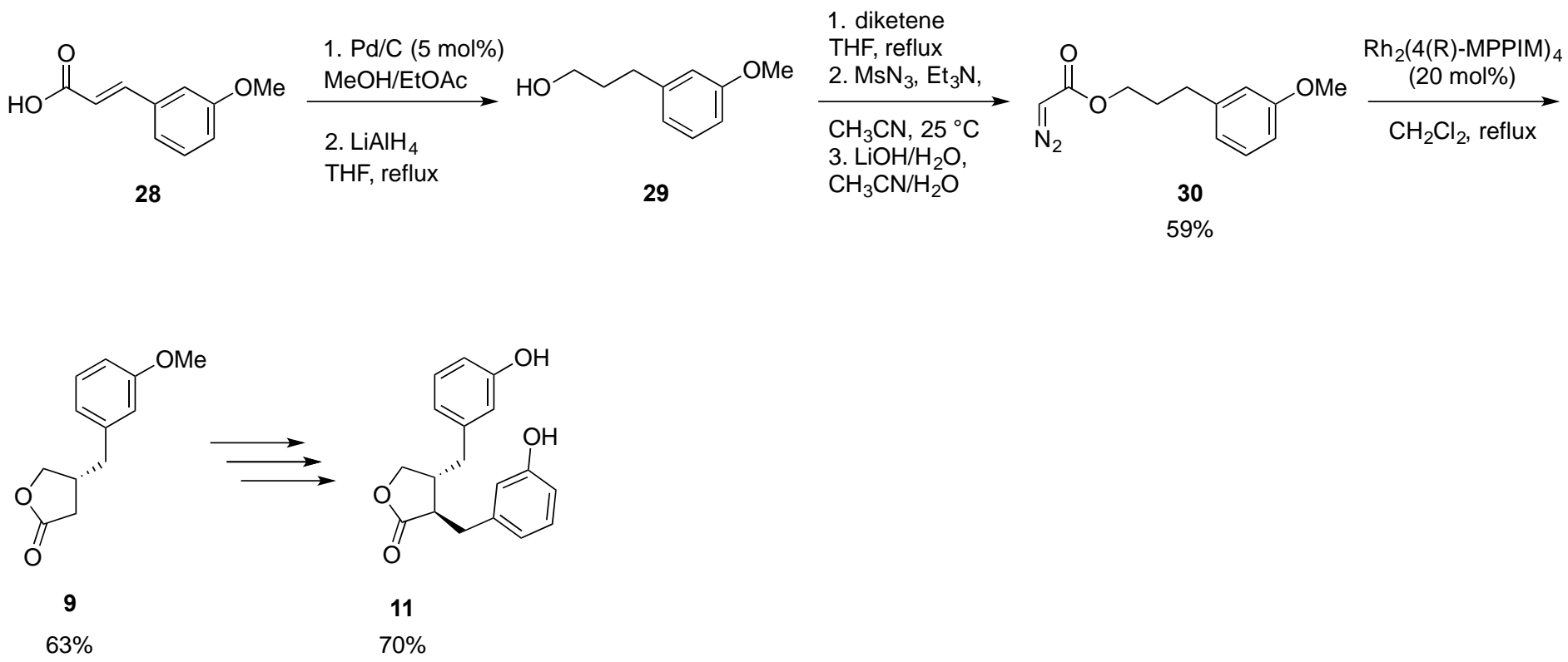

Scheme 8. Synthesis of (-)-enterolactone with the use of $\mathrm{Rh}_{2}(4(R)-\mathrm{MPPIM})_{4}$ catalyst by Doyle et al. ${ }^{50}$

Yan and Spilling's total synthesis of (-)-enterolactone had high enantioenrichment and incorporated two transition metal-catalyzed steps (Scheme 9). ${ }^{45}$ Cinnamaldehyde, 31, was treated with a chiral catalyst, prepared from titanium isopropoxide and dimethyl L-tartrate as the chiral ligand, to provide the $\alpha$-hydroxy phosphonate 32 in $95 \%$ ee upon recrystallization. ${ }^{52}$ A ruthenium-catalyzed cross-metathesis of 32 with 3- $(m-$ methoxyphenyl)propene gave $\mathbf{3 3}$ in $36 \%$ yield and $95 \%$ ee. Methyl chloroformate was then used to form a carbonate from the hydroxy phosphonate. Palladium-catalyzed addition to a malonate provided $\mathbf{3 5}$ in $85 \%$ yield with a slight loss in ee ( $95 \%$ to $92 \%$ ee). Ozonolysis was used to cleave the dimethoxy phosphinyl group, forming an aldehyde intermediate. This intermediate cyclized upon reduction with $\mathrm{NaBH}_{4}$ to form the lactone 36 . Decarboxylation with lithium chloride in DMSO provided a highly enantiopure enterolactone precursor, 9, which was converted into (-)-enterolactone, 11, using Sibi's protocol (Scheme 3).

Eklund and colleagues were also able to complete a semisynthesis of (-)-enterolactone from lignan hydroxymatairesinol with the use of a palladium catalyst (Scheme 10). ${ }^{53}$ This readily available lignan isolated from the Norway spruce (Picea abies) undergoes hydrogenation to provide matairesinol, followed by esterification resulting in the intermediate 38. The intermediate $\mathbf{3 8}$ was converted into $\mathbf{1 0}$ by a palladiumcatalyzed deoxygenation reaction and demethylation affording (-)-enterolactone, 11, in an overall yield of 55\%. 


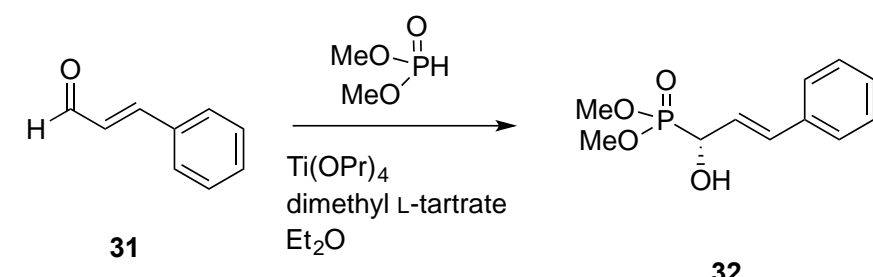

$78 \%$

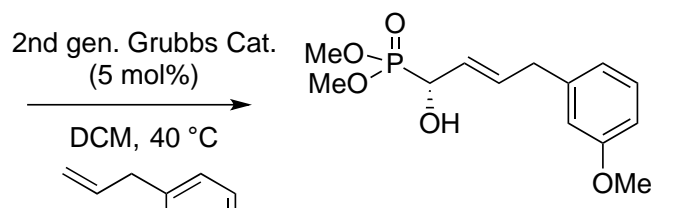

33

$26 \%$
$\underset{\mathrm{CH}_{2} \mathrm{Cl}_{2}}{\stackrel{\mathrm{Py}, \mathrm{ClCO}_{2} \mathrm{Me}}{\longrightarrow}}$

$\mathrm{LiCl}$
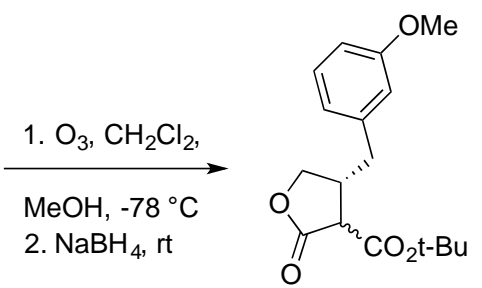

36

$57 \%$<smiles>COc1cccc(C[C@H]2COC(=O)C2)c1</smiles>

9

$65 \%$
35

$85 \%$<smiles>O=C1OC[C@H](Cc2cccc(O)c2)[C@@H]1Cc1cccc(O)c1</smiles>

11

Scheme 9. Catalytic synthesis of (-)-enterolactone by Yan and Spilling. ${ }^{45}$<smiles>COc1cc(C[C@H]2C(=O)OC[C@@H]2C(O)c2ccc(O)c(OC)c2)ccc1O</smiles>

37

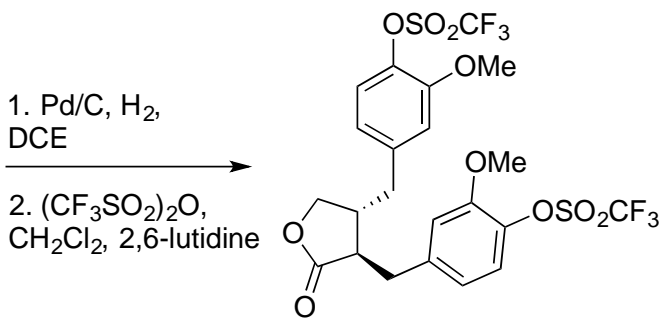

38

$88 \%$

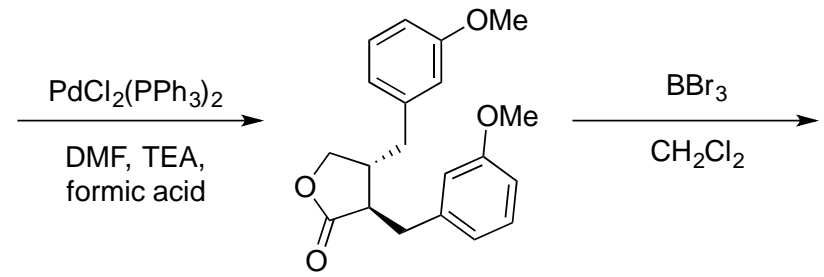

10

$85 \%$<smiles>O=C1OC[C@H](Cc2cccc(O)c2)[C@@H]1Cc1cccc(O)c1</smiles>

11

$79 \%$

Scheme 10. Semisynthesis of (-)-enterolactone by Eklund et al. ${ }^{53}$ 
The total synthesis of enterolactone by Isemori et al. began with the formation of an organocuprate which added via oxidative nucleophilic substitution onto 39, resulting in an inversion of stereochemistry (Scheme 11). 51,54

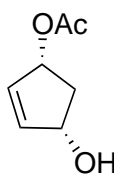

39

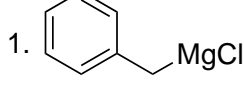

CuCN (30 mol\%)

THF, $-18^{\circ} \mathrm{C}$

2. TBSCl

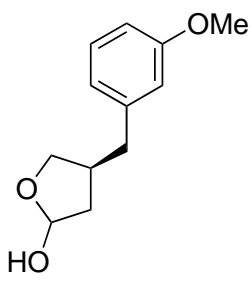

42

$97 \%$

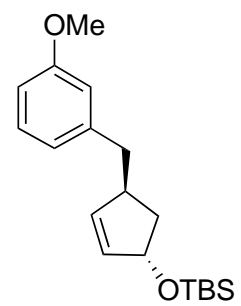

40

$80 \%$

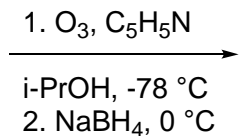

2. $\mathrm{NaBH}_{4}, 0^{\circ} \mathrm{C}$

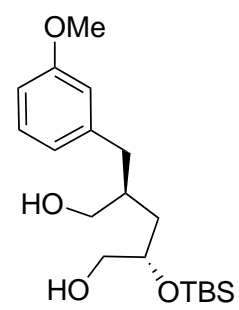

41

$81 \%$
1. TBAF

2. $\mathrm{KIO}_{4}$ $\mathrm{EtOH} / \mathrm{H}_{2} \mathrm{O}$

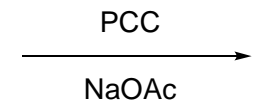

$\mathrm{MeO}_{2} \mathrm{C} \frown \mathrm{CHO}$

44<smiles>COc1cccc(C[C@@H]2COC(=O)[C@H]2Cc2cccc(OC)c2)c1</smiles>

10

$68 \%$
1. 3- $\mathrm{MeOC}_{6} \mathrm{H}_{4} \mathrm{CHO}$ L-proline (20 mol\%),

DMF, $4{ }^{\circ} \mathrm{C}$

2. $\mathrm{NaBH}_{4}, \mathrm{MeOH}$, $40^{\circ} \mathrm{C}$
44

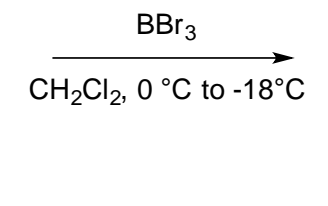

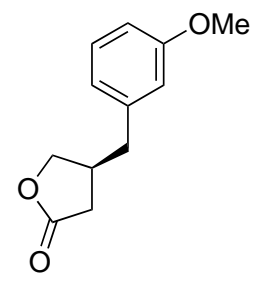

43

$95 \%$

13

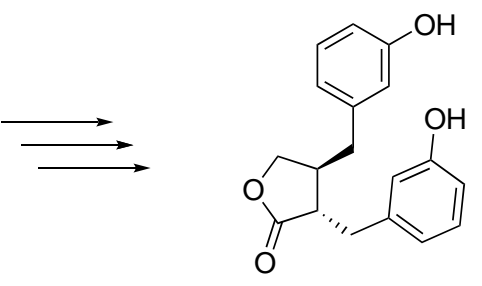

Scheme 11. Synthesis of (+)-enterolactone with Grignard and copper(I) cyanide by Isemori et al. ${ }^{51}$

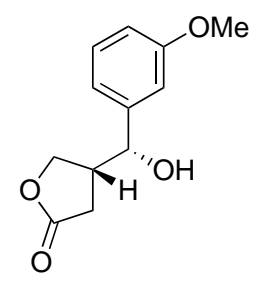

45 $55 \%$<smiles>O=C1OC[C@H](Cc2cccc(O)c2)[C@H]1Cc1cccc(O)c1</smiles>

11

$87 \%$

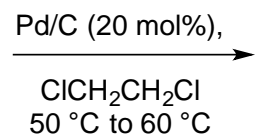<smiles>COc1cccc(C[C@H]2COC(=O)C2)c1</smiles>

$\underset{\text { 3-MeOC }{ }_{6} \mathrm{H}_{4} \mathrm{CH}_{2} \mathrm{Br} \text {, }}{\longrightarrow}$ THF, $-78^{\circ} \mathrm{C}$ to $-54^{\circ} \mathrm{C}$

Scheme 12. Synthesis of (-)-enterolactone with use of L-proline by Hajra et al. ${ }^{55}$

Hajra et al. developed a short synthesis for the preparation of (-)-enterolactone using a crossed-aldol reaction. ${ }^{55}$ The starting material, 4-oxobutyrate 44 , was added to a mixture of 3-methoxybenzaldehyde and L- 
proline to create a reactive chiral imine (Scheme 12). This intermediate was then reduced with sodium borohydride to afford 45. Compound $\mathbf{4 5}$ underwent reduction with the use of palladium over carbon. The reduced intermediate, $\mathbf{4 6}$, was subjected to alkylation to afford compound $\mathbf{1 0}$. The final step incorporated the use of boron tribromide to generate the product, 11 , in an overall yield of $23 \%$.

\subsubsection{Desymmetrization using enzymes.}

Enzymes are excellent catalysts for carrying out a variety of asymmetric transformations. ${ }^{56}$ Chênevert and coworkers employed Pseudomonas cepacia lipase to obtain the optically active monoester 49 selectively. ${ }^{57} \mathrm{~A}$ diester, 47, was initially reduced with lithium aluminum hydride to generate the corresponding diol, 48, which reacted with lipase and vinyl acetate to provide the monoacetate 49 (Scheme 13). Compound 49 was then treated with mesyl chloride and triethylamine to furnish the mesylated adduct. Nucleophilic substitution using cyanide generated the corresponding nitrile 50, which was hydrolyzed. The carboxylic acid intermediate underwent ring closure to furnish lactone 9. From this point, a methodology similar to Sibi's total synthesis (Scheme 3) was employed, providing (-)-enterolactone, 11, in an overall yield of 33\%.

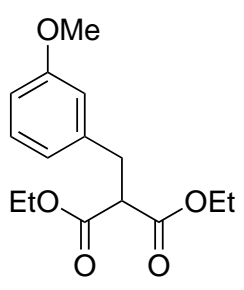

47

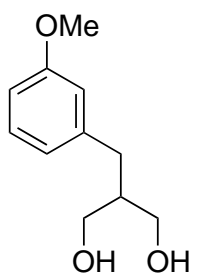

48

$75 \%$
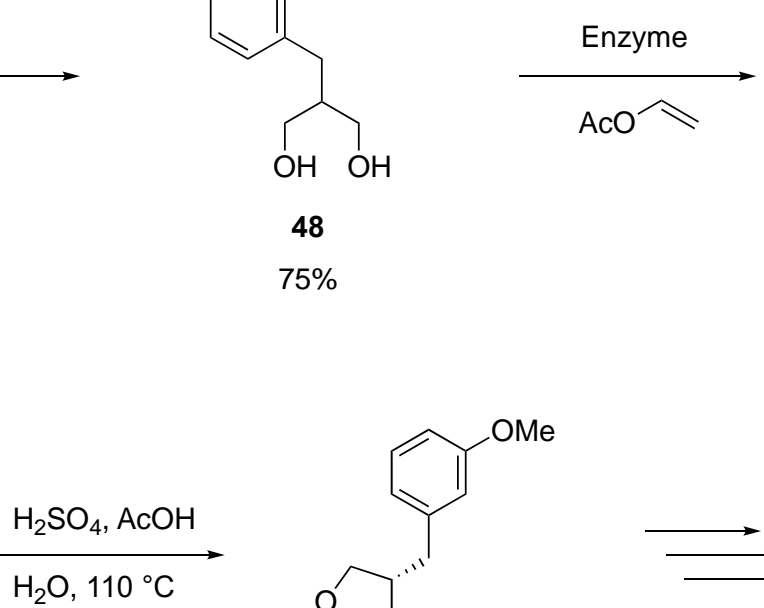

OAc CN

50

$96 \%$

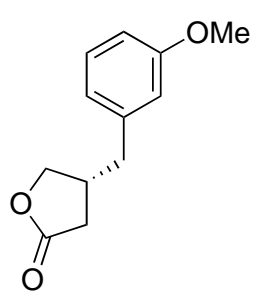

9

$94 \%$

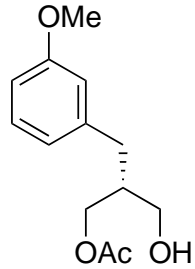

49

$94 \%$

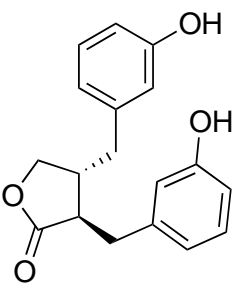

11

$52 \%$

Scheme 13. Synthesis of (-)-enterolactone with Pseudomonas cepacia lipase by Chênevert et al. ${ }^{57}$

\subsubsection{One-pot synthesis of enterolactone}

The total syntheses of enterolactone discussed so far have installed the chiral centers in a stepwise fashion. In this section, the tandem conjugate addition-alkylation protocol for the formation of both chiral centers will be discussed. The goal of this strategy is to reduce the number of steps and increase the overall yield. Van Oeveren et al. were able to employ this tandem strategy to generate (-)-enterolactone, 11, using an enantiomerically pure butenolide as the Michael acceptor (Scheme 14). ${ }^{58}$ In this synthesis, the butenolide underwent conjugate addition by a benzylic dithioacetal, $\mathbf{5 1}$. The resulting enolate, $\mathbf{5 2}$, was then quenched with a benzyl bromide to form 53 in $67 \%$ yield. In a one-pot procedure, the thioacetal $\mathbf{5 3}$ underwent desulfurization with nickel boride, formed in situ from nickel(II) chloride and sodium borohydride. This was followed by the addition of $\mathrm{KOH}$ and more sodium borohydride to afford 54, followed by work up with $\mathbf{H C l}$ to result in $\mathbf{5 5}$. Finally, the disubstituted 
lactone was deprotected with palladium over carbon, resulting in the (-)-enterolactone product, 11.
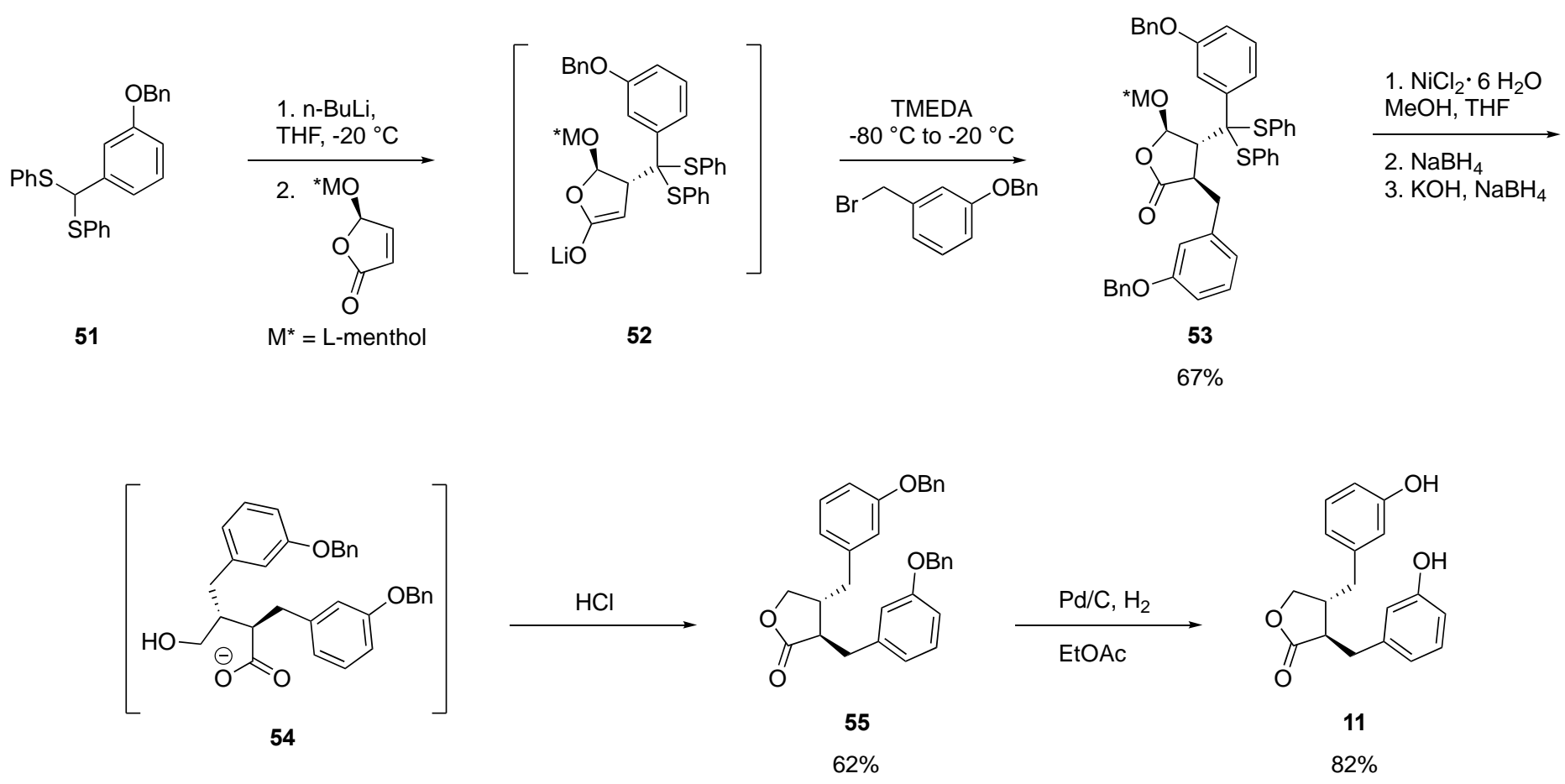

Scheme 14. Tandem synthesis of (-)-enterolactone by Van Oeveren et al. ${ }^{58}$

\section{Conclusions}

Lignan, which is converted into enterolactone when digested by mammals, is found in a variety of foods such as vegetables, flax seed, whole grain foods and fruits. It has been shown that a high lignan intake correlates with high levels of enterolactone found in the circulatory system. While some reports state that enterolactone possesses anticancer, antivascular, antiviral, antibacterial and antistroke properties, others contradict this claim with studies showing that there is no correlation between intake of lignan and reduction of these diseases. Other studies suggest that high levels of enterolactone negatively affect male fertility. The inconsistency in the literature is due to the heterogeneity of the populations studied. The level of enterolactone is dependent on participants' age, sex, intestinal flora, use of antibiotics, and ability to break down lignan. All these factors were not consistently accounted for during the course of these studies, leading to inconclusive results. Despite this uncertainty, chemists have developed various methods to synthesize enterolactone stereoselectively through the use of radical reactions, Michael additions, organometallic chemistry and enzymatic reactions.

\section{Acknowledgements}

We thank NIH (GM-54656) and North Dakota State University for financial support of our program on lignan synthesis. We also thank Anna Renner for editorial assistance. 


\section{References}

1. Ayres, D. C.; Loike, J. D. Lignans: Chemical, Biological and Clinical Properties; Cambridge University: Cabridge, 1990.

2. Allais, F.; Pla, T. J. L.; Ducrot, P. H. Synthesis 2011, 1456.

http://dx.doi.org/10.1055/s-0030-1259982

3. Del Signore, G.; Berner, O. M. Stud. Nat. Prod. Chem. 2006, 33, 541.

4. Lindsley, C. W.; Hopkins, C. R.; Sulikowski, G. A. Biomimetic Synthesis of Lignans. In Biomimetic Organic Synthesis; Poupon, E.; Nay, B., Eds; Wiley-VCH Verlag GmbH \& KGaA: Weinheim, 2011; Vol. 2, 677.

http://dx.doi.org/10.1002/9783527634606.ch18

5. Magoulas, G. E.; Papaioanou, D. Molecules 2014, 19, 19769.

http://dx.doi.org/10.3390/molecules191219769

6. Teponno, R. B.; Kusari, S.; Spiteller, M. Nat. Prod. Rep. 2016, 33, 1044. http://dx.doi.org/10.1039/C6N)00021E

7. Topcu, G.; Demirkiran, O. Top. Heterocycl. Chem. 2007, 11, 103. http://dx.doi.org/10.1007/7081 2007082

8. Ward, R. S. Chem. Soc. Rev. 1982, 11, 75. http://dx.doi.org/10.1039/CS9821100075

9. Ward, R. S. Tetrahedron 1990, 46, 5029. http://dx.doi.org/10.1016/S0040-4020(01)87810-8

10. Pan, J.-Y.; Chen, S.-L.; Yang, M.-H.; Wu, J.; Sinkkonen, J.; Zou, K. Nat. Prod. Rep. 2009, 26, 1251. http://dx.doi.org/10.1039/B910940D

11. Milder, I. E. J.; Arts, I. C. W.; van de Putte, B.; Venema, D. P.; Hollman, P. C. H. Br. J. Nutr. 2005, $93,393$. http://dx.doi.org/10.1079/BJN20051371

12. Saleem, M.; Kim, H. J.; Ali, M. S.; Lee, Y. S. Nat. Prod. Rep. 2005, 22, 696. http://dx.doi.org/10.1039/B514045P

13. Jansen, G. H. E.; Arts, I. C. W.; Nielen, M. W. F.; Müller, M.; Hollman, P. C. H.; Keijer, J. Arch. Biochem. Biophys. 2005, 435, 74.

http://dx.doi.org/10.1016/j.abb.2004.12.015

14. Mäkelä, T. H.; Wähälä, K. T.; Hase, T. A. Steroids 2000, 65, 437. http://dx.doi.org/10.1016/S0039-12X(00)00104-5

15. Axelson, M.; Setchell, K. D. FEBS Lett. 1981, 123, 337. http://dx.doi.org/10.1016/S0140-6736(81)90250-6

16. Keinan-Boker, L.; Van Der Schouw, Y. T.; Grobbee, D. E.; Peeters, P. H. M. Am. J. Clin. Nutr. 2004, 79, 282.

17. Kilkkinen, A.; Valsta, L. M.; Virtamo, J.; Stumpf, K.; Adlercreutz, H.; Pietinen, P. J. Nutr. 2003, 133, 1830.

18. Miles, F. L.; Navarro, S. L.; Schwarz, Y.; Gu, H.; Djukovic, D.; Randolph, T. W.; Shojaie, A.; Kratz, M.; Hullar, M. A. J.; Lampe, P. D.; Neuhouser, M. L.; Raftery, D.; Lampe, J. W. Food Funct. 2017, 8, 3209. http://dx.doi.org/10.1039/C7FO00684E

19. Setchell, K.; Boriello, S.; Gordon, H.; Lawson, A.; Harkness, R.; Morgan, D.; Kirk, D.; Adlercreutz, H.; Anderson, L.; Alexon, M. Lancet 1981, 318, 4. http://dx.doi.org/10.1016/S0140-6736(81)90250-6

20. Adlercreutz, H.; Fotsis, T.; Heikkinen, R.; Dwyer, J. T.; Goldin, B. R.; Gorbach, S. L.; Lawson, A. M.; Setchell, K. D. R. Med Biol. 1981, 59, 259.

21. Wallström, P.; Drake, I.; Sonestedt, E.; Gullberg, B.; Bjartell, A.; Olsson, H.; Adlercreutz, H.; Tikkanen, M. J.; Wirfält, E. Eur. J. Nutr. 2017, 1. 
http://dx.doi.org/10.1007/s00394-017-1530-z

22. Kuiper, G. G.; Lemmen, J. G.; Carlsson, B.; Corton, J. C.; Safe, S. H.; van der Saag, P. T.; van der Burg, B.; Gustafsson, J. Endocrinology 1998, 139, 4252.

http://dx.doi.org/10.1210/endo.139.10.6216

23. Adlercreutz, H.; Mazur, W. Ann. Med. 1997, 29, 95. http://dx.doi.org/10.3109/07853899709113696

24. Brodie, A. J. Steroid Biochem. Mol. Biol. 1991, 40, 255. http://dx.doi.org/10.1016/0960-0760(91)90190-G

25. Wang, C.; Mäkelä, T.; Hase, T.; Adlercreutz, H.; Kurzer, M. S. J. Steroid Biochem. Mol. Biol. 1994, 50, 205. http://dx.doi.org/10.1016/0960-0760(94)90030-2

26. Vanharanta, M.; Voutilainen, S.; Rissanen, T. H.; Adlercreutz, H.; Salonen, J. T. Arch. Intern. Med. 2003, $163,1099$. http://dx.doi.org/10.1001/archinte.163.9.1099

27. O’Donnell, L.; Robertson, K. M.; Jones, M. E.; Simpson, E. R. Endocr. Rev. 2001, 22, 289. http://dx.doi.org/10.1210/edrv.22.3.0431

28. Chavarro, J. E.; Toth, T. L.; Sadio, S. M.; Hauser, R. Hum. Reprod. 2008, 23, 2584. http://dx.doi.org/10.1093/humrep/den243

29. Xia, Y.; Chen, M.; Zhu, P.; Lu, C.; Fu, G.; Zhou, X.; Chen, D.; Wang, H.; Hang, B.; Wang, S.; Zhou, Z.; Sha, J.; Wang, X. Environ. Int. 2013, 59, 161.

http://dx.doi.org/10.1016/i.envint.2013.06.009

30. Suzuki, S.; Umezawa, T. J. Wood Sci. 2007, 53, 273. http://dx.doi.org/10.1007/s10086-007-0892-x

31. Kim, K. W.; Moinuddin, S. G. A.; Atwell, K. M.; Costa, M. A.; Davin, L. B.; Lewis, N. G. J. Biol. Chem. 2012, $287,33957$. http://dx.doi.org/10.1074/jbc.M112.387423

32. Lewis, N. G.; Davin, L. B.; Sarkanen, S. Lignin and Lignan Biosynthesis:Distinctions and Reconciliations. In Lignin and Lignan Biosynthesis; ACS Symposium Series 697; American Chemical Society: Washington, DC, 1998; 1. http://dx.doi.org/10.1021/bk-1998-0697.ch001

33. Borriello, S. P.; Setchell, K. D. R.; Axelson, M.; Lawson, A. M. J. Appl. Bacteriol. 1985, 58, 37. http://dx.doi.org/10.1111/j.1365-2672.1985.tb01427.x

34. Groen, M. B.; Leemhuis, J. Tetrahedron Lett. 1980, 21, 5043. http://dx.doi.org/10.1016/S0040-4039(00)71128-2

35. Cooley, G.; Farrant, R. D.; Kirk, D. N.; Wynn, S. Tetrahedron Lett. 1981, 22, 349. http://dx.doi.org/10.1016/0040-4039(81)80094-9

36. Mahalanabis, K. K.; Mumtaz, M.; Snieckus, V. Tetrahedron Lett. 1982, 23, 3975. http://dx.doi.org/10.1016/S0040-4039(00)88673-6

37. Asaoka, M.; Fujii, N.; Shima, K.; Takei, H. Chem. Lett. 1988, 805. http://dx.doi.org/10.1246/cl.1988.805

38. Ghosh, M. Tetrahedron 2007, 63, 11710. http://dx.doi.org/10.1016/j.tet.2007.08.103

39. Srikrishna, A.; Venkateswarlu, S.; Denieldoss, S.; Sattigeri, J. A. J. Indian Chem. Soc. 1995, 34B, 679.

40. Srikrishna, A.; Danieldoss, S.; Venkateswalu, S.; Sattigeri, J. A. J. Indian Chem. Soc. 1997, 74, 864.

41. Bambagiotti-Alberti, M.; Coran, S. A.; Vincieri, F. F.; Mulinacci, N.; Pieraccini, G. M. L. Heterocycles 1988, $27,2185$. http://dx.doi.org/10.3987/COM-88-4321

42. Bambagiotti-Alberti, M.; Coran, S. A.; Vincieri, F. F.; Nostro, P. L. Heterocycles 1987, $26,1735$. http://dx.doi.org/10.3987/R-1978-07-1735 
43. Pelter, A.; Ward, R. S.; Satyanarayana, P.; Collins, P. J. Chem. Soc., Perkin Trans. 1 1983, 643. http://dx.doi.org/10.1039/P19830000643

44. Evans, D. A.; Bartroli, J.; Shih, T. L. J. Am. Chem. Soc. 1981, 103, 2127. http://dx.doi.org/10.1021/ia00398a058

45. Yan, B.; Spilling, C. D. J. Org. Chem. 2004, 69, 2859. http://dx.doi.org/10.1021/j0035795h

46. Sibi, M. P.; Liu, P.; Johnson, M. D. Can. J. Chem. 2000, 78, 133. http://dx.doi.org/10.1139/v99-220

47. Sibi, M. P.; Liu, P.; Ji, J.; Hajra, S.; Chen, J.-X. J. Org. Chem. 2002, 67, 1738. http://dx.doi.org/10.1021/jo015501x

48. Evans, D. A.; Ennis, M. D.; Mathre, D. J. J. Am. Chem. Soc. 1982, 104, 1737. http://dx.doi.org/10.1021/ja00370a05

49. Yoda, H.; Kitayama, H.; Katagiri, T.; Takabe, K. Tetrahedron 1992, 48, 3313. http://dx.doi.org/10.1016/0040-4020(92)85007-2

50. Doyle, M. P.; Protopopova, M. N.; Zhou, Q. L.; Bode, J. W.; Simonsen, S. H.; Lynch, V. J. Org. Chem. 1995, 60, 6654. http://dx.doi.org/10.1021/jo00126a002

51. Isemori, Y.; Kobayashi, Y. Synlett 2004, 1941. http://dx.doi.org/10.1055/s-2004-830890

52. Bode, J. W.; Doyle, M. P.; Protopopova, M. N.; Zhou, Q. L. J. Org. Chem. 1996, 61, 9146. http://dx.doi.org/10.1021/jo961607u

53. Eklund, P.; Lindholm, A.; Mikkola, J. P.; Smeds, A.; Lehtilä, R.; Sjöholm, R. Org. Lett. 2003, 5, 491. http://dx.doi.org/10.1021/ol0273598

54. Ito, M.; Matsuumi, M.; Murugesh, M. G.; Kobayashi, Y. J. Org. Chem. 2001, 66, 5881. http://dx.doi.org/10.1021/jo010474w

55. Hajra, S.; Giri, A. K.; Hazra, S. J. Org. Chem. 2009, 74, 7978. http://dx.doi.org/10.1021/jo900810a

56. Rachwalski, M.; Vermue, N.; Rutjes, F. P. J. T. Chem. Soc. Rev. 2013, 42, 9268. http://dx.doi.org/10.1039/c3cs60175g

57. Chênevert, R.; Mohammadi-Ziarani, G.; Caron, D.; Ohammed, D. M. Can. J. Chem. 1999, 77, 223. http://dx.doi.org/10.1139/v98-231

58. Van Oeveren, A.; Jansen, J. F. G. A.; Feringa, B. L. J. Org. Chem. 1994, $59,5999$. http://dx.doi.org/10.1021/jo00099a033

\section{Authors' Biographies}

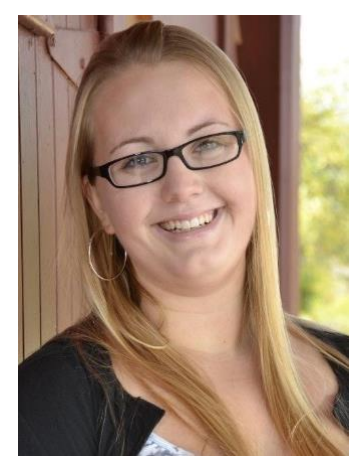

Quinlyn Waulters studied Biochemistry at Saint Mary's University of Minnesota, obtaining her BA in 2016. She 
started attending North Dakota State University in 2016 and joined the Sibi research group in 2017. Currently, she is working with achiral templates and Lewis acids to develop contiguous chiral centers selectively.

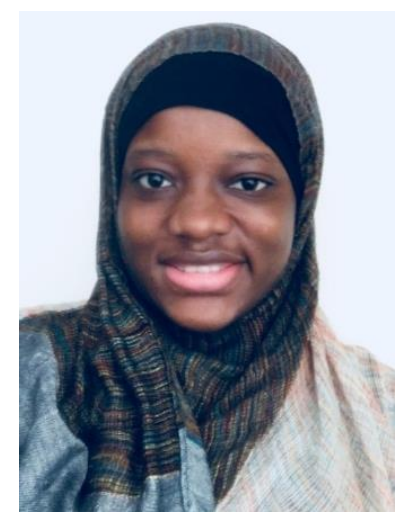

Waidath Bio-Sawe received her BSc in Biochemistry at St Cloud State University, MN, in 2015. She joined the Sibi research group in 2016 at North Dakota State University and is currently working in the area of cooperative catalysis.

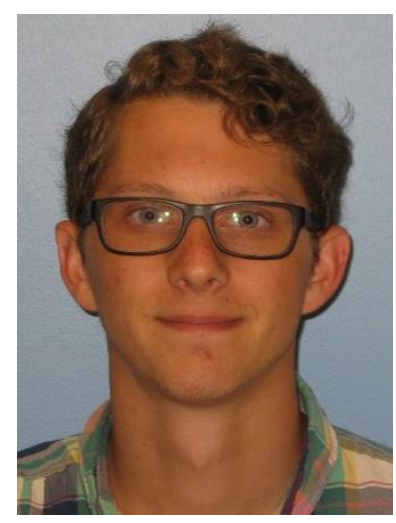

Russell Hofmann graduated from lowa State University in 2015 with a BSc in biochemistry. He began attending North Dakota State University in 2016 and joined the Sibi research group in 2017. His research studies include Lewis acid catalysis and achiral template design.

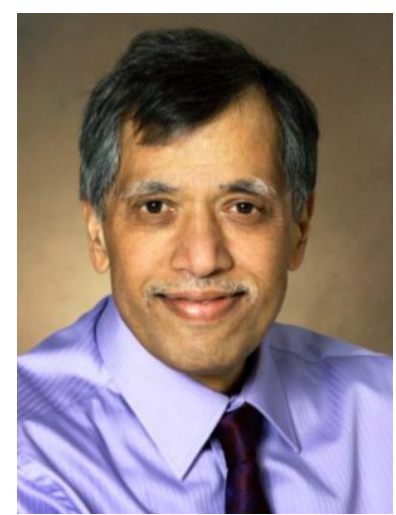

Prof. Mukund Sibi began his independent career at North Dakota State University, where he is currently a University Distinguished Professor. His research focus is on radical chemistry, catalysis, and green chemistry. He has received a number of awards in recognition of his scientific contributions, including the A. C. Cope Scholar award in 2008. 